\title{
Umande Trust Bio-Centre Approach in Slum Upgrading
}

\section{Aidah Binale}

\section{Q OpenEdition}

1 Journals

\section{Electronic version}

URL: https://journals.openedition.org/eastafrica/543

DOI: $10.4000 /$ eastafrica. 543

ISSN: 2790-1076

\section{Publisher}

IFRA - Institut Français de Recherche en Afrique

\section{Printed version}

Date of publication: 1 September 2011

Number of pages: 167-185

ISSN: 2071-7245

\section{Electronic reference}

Aidah Binale, "Umande Trust Bio-Centre Approach in Slum Upgrading", Les Cahiers d'Afrique de l'Est / The East African Review [Online], 44 | 2011, Online since 07 May 2019, connection on 09 December 2021. URL: http://journals.openedition.org/eastafrica/543 ; DOl: https://doi.org/10.4000/eastafrica. 543

This text was automatically generated on 9 December 2021.

Les Cahiers d'Afrique de l'Est / The East African Review 


\title{
Umande Trust Bio-Centre Approach in Slum Upgrading
}

\author{
Aidah Binale
}

\section{Background}

1 Umande Trust (UT) is a rights-based agency which believes that modest resources can significantly improve access to water and sanitation services if financial resources are strategically invested in support of community-led plans and actions. We maintain excellent rapport with community-based groups, organizations and coalitions in most informal settlements in Nairobi, Kisumu and Dallas in Embu. This extensive reach, with people and partner agencies, continues to register promising results. We believe in working with communities to adopt technologies which address water and sanitation problems and the choice of ecological sanitation is firmly rooted in this goal.

2 The underlying philosophy of ecological sanitation, hereafter referred to as ablution blocks (bio-centres), is that if treated properly, human waste is a valuable resource. The period of 2005-2015 is the United Nations (UN) decade of fresh water and basic sanitation. UT is committed to actively contribute to the UN Millennium Development Goal (MDG) "to halve the number of people living without sustainable access to safe (and affordable) drinking water and to basic sanitation by 2015" guided by the following principles: (1) equity (easily accessible to the population); (2) affordability; (3) environmental effectiveness (pollution prevention and health promotion) and (4) sustainability (limited cross-subsidy which is maintained and accepted by communities).

Over the years, residents in informal settlements in Nairobi have had to cope with water shortage and poor sanitation conditions. It is estimated that $95 \%$ of residents living in slums draw water from individually-owned, illegal water standpipes at exorbitant prices. Besides, water quality is compromised due to use of sub-standard and broken/bursting pipes leading to water contamination from surface waste water whenever there are leakages/bursts. Furthermore, $75 \%$ of the population lack toilet 
facilities within their homes and most residents use dilapidated toilets or flying toilets that are emptied into nearby rivers, leading to water pollution.

4 To address the above challenges, Athi Water Service Board (AWSB) developed strategic guidelines that seek to improve water and sanitation services in Nairobi's informal settlements (Kibera, Korogocho and Mukuru). The project was funded through the Nairobi Water and Sewerage Emergency Physical Investments Project (CKE 3005) Package 4 Construction of Ablution Blocks in Informal Settlements in Nairobi. This was part of a funding agreement between the French Development Agency (AFD) and the Government of Kenya, entitled "Nairobi Water and Sewerage Emergency Physical Investments Programme (NWSEPIP)." The project was financed by AFD through AWSB and the memorandum of Agreement (MoA) between AWSB and Umande Trust was signed on 6 August, 2007. The bio-centres have improved water and sanitation in the area, hence contributing to the reduction of related problems and access costs while fostering cohesion in the community, among other benefits.

\section{Bio-Centre Projects in Korogocho, Kibera and Mukuru (August 2007-September 2009)}

\section{Location Details}

5 Together with development partners, UT has developed and implemented projects that are aimed at improving access to safe water and sanitation for informal settlement dwellers. One major project was the construction of 20 ablution blocks (also called biocentres) in selected villages of Korogocho, Kibera and Mukuru informal settlements, targeted to benefit 350,000 residents.

\section{Korogocho}

6 Korogocho is the fourth largest informal settlement in Nairobi and it borders the largest dumping site in Kenya i.e. Dandora. The area is $95 \%$ government-owned land and has 8 villages. The area is characterized by inaccessibility to minimum services and infrastructure, lack of security of tenure, HIV/AIDS, water and air borne diseases, high unemployment rates, occasional violent conflicts and high rates of insecurity. Settlement in Korogocho dates from the 1960s, when it was a settlement for quarry workers, and the late 1970s as a result of the demolition of informal settlements close to the city and the resettlement of the squatters there. 
Figure 1: Tegemeo Bio-centre, Korogocho Market

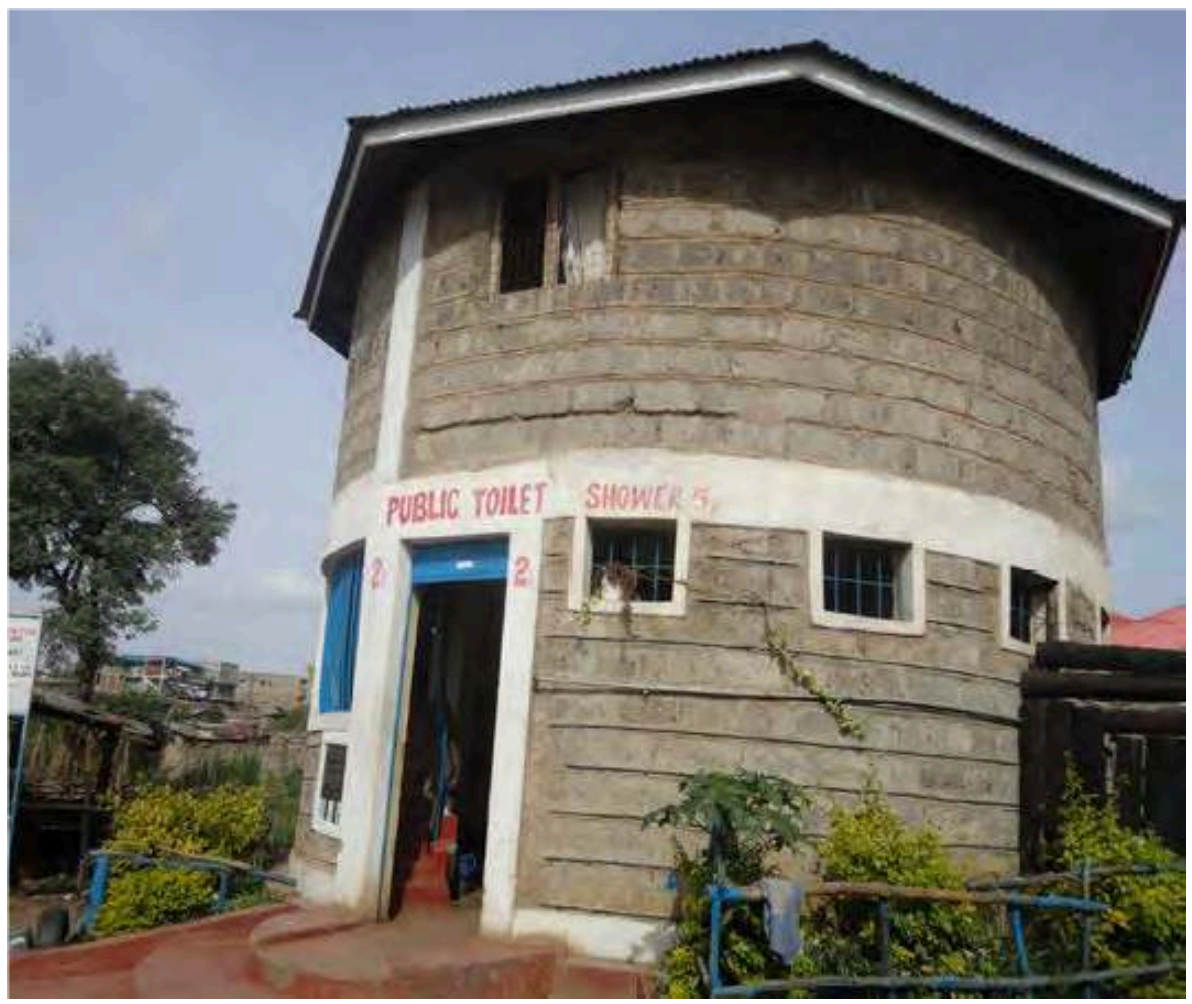

Source: Umande Trust (2011)

\section{Kibera}

7 The recent census carried out by the Government of Kenya (GOK) in 2009 puts the population of Kibera at 170,070 (GOK, 2009). Kibera is located on a hill crossed by three rivers that join downstream on the south east. Before the 1990s, this water was used for all purposes but these days, the rivers have become polluted with sewage that sometimes get blocked by garbage. The management of waste and waste water is currently one of the major problems of urban informal settlements.

Kibera, like many other settlements in Nairobi, is characterized by lack of basic services and infrastructure such as adequate access to water, sanitation, garbage collection, roads and footpaths, storm drainage, electricity and public lighting etc. Housing units are semi-permanent in nature and often reflective of the high population densities. Security of tenure is not guaranteed and the threat of forced eviction remains real. Social amenities are inadequate with facilities such as schools and hospitals unable to cope with the population demand.

9 Services are therefore essentially private or provided by non-profit organizations. The government seems to rely on Non-Governmental Organisations (NGOs) or institutions such as UN-HABITAT. For example, the Ministry of Health is a partner of Doctors Without Borders (MSF Belgium) clinics and the Ministry of Lands is taking part in the UN-HABITAT up-grading program in Soweto East. The privatization of the distribution of portable water brought problems, particularly with regard to unstable prices (a 201 jerrican rates from KSh 5 to 20 , in case of scarcity i.e. USD 0.05-0.21) and poor quality of the maintenance of pipes. These plastic pipes often lie in open drains occasionally filled 
with raw sewage which cause contamination of the water. As toilets and bathroom facilities are not provided in houses, this sector is managed through private toilets at a cost of KSh 3-5 (USD 0.03-0.05). Consequently, many people prefer the use of the infamous "flying toilets" which is free.

\section{Mukuru}

In terms of surface area, Mukuru is almost as large as Kibera. Mukuru, which means valley in $\mathrm{Kikuyu}^{1}$, was started in the 1970s by workers from the nearby quarries and it has grown rapidly in the last five years. The physical geography of Mukuru makes it difficult to access thus renders issues of water and sanitation more complex. The swampy soil does not permit the escape of waste water, which then stagnates, consequently contributing to diseases such as cholera, malaria and typhoid fever.

11 It is said that "water is life and sanitation is dignity"; this dignity is absent throughout most of the expansive slum. The poor sanitation conditions found here are aggravated by lack of planning which characterizes most informal settlements. The residents live in squalid conditions occupying tiny semi-permanent structures built from flimsy material such as timber, cardboard, plastic and corrugated iron sheets. These structures house numbers far beyond their capacity. Water and sanitation issues are similar to those of Kibera and Korogocho. Although water connection has been improved previously by Nairobi City Water and Sewerage Company (NCWSC), some areas are still suffering from gang/cartels' rules in water distribution. In Mukuru Kwa Njenga, in the event of water scarcity, 20 litres of water can go up to KSh 40 (USD 0.43). The need for proper sanitation and better access to water is fundamental in this informal settlement where the sanitary situation is critical. This becomes a health hazard to people staying in this area.

\section{Bio-centre Project Goal}

12 The overall goal of the bio-centre project is to promote improved sanitation in selected low-income areas of Nairobi through the provision of ablution blocks and training in both managing the facility and improved hygiene. This is in line with the AWSB informal settlements strategy whose overall objective is to provide reliable, affordable and sustainable access to safe drinking water and basic sanitation to people living in informal settlements. The definition is contained within the Kenyan Water Services Strategy whose main aim is to achieve the specific MDGs and WSS targets on water and sanitation for the country by 2015 .

The specific objectives of this project are:

- Increased hygiene in the informal settlements through improved water availability and sanitation hence reduction in incidence diseases;

- Improved water and sanitation in each informal settlement by regularization and control of the water and sanitation facilities;

- Provision of a sustainable source of water to the informal settlements;

- Reduction of the cost of water and sanitation services in the informal settlements where the project is to be implemented;

- Creation of jobs in the informal settlements by way of creating awareness through training of $\mathrm{CBOs}$ to operate and manage the sanitation kiosks for a fee; 
- To raise awareness of what sustainable sanitation solutions are and promoting them on a large scale;

- To highlight the key role of sanitation to achieve a whole series of MDGs;

- To show how sustainable sanitation projects should be planned with participation of all stakeholders (hand in hand with hygiene promotion and capacity development).

\section{Process and Management/Implementation Strategies} participation of all stakeholders. The scope of activities included initial research to determine the scale and location of the toilets, determining and training the group which will operate the toilets and the actual construction of the Building. All of the activities involved the relevant stakeholders, for instance NWSC staff participated in the various training workshops and community members, through organized groups, participated in construction and managing the facility.

\section{Research, Training and Awareness}

activities started with a survey to determine the number of users and their attitudes to fees for use and additional services. this involved quantifying the number of households in the informal settlements to establish potential demand so as to guide the design process. a quantitative survey was carried out using a questionnaire which was developed By the UT team. The questionnaire covered various issues categorized by sex, gender and the area(s) the respondent(s) lived in. The three settlements covered in the survey were

Korogocho, Kibera and Mukuru informal settlements. The sanitation characteristics were determined by availability of built water, latrine and bathroom facilities. The survey sought to determine their source, their cost and their distance to settlements in the three informal areas sampled. The characteristics of water targeted were: (1) source; (2) distance to source and (3) cost of water. The characteristics of latrines and those of bathrooms were equally defined by: (1) source; (2) distance to source and (3) cost to the settlements. The sample targeted 50 respondents in geographically distributed sub-areas in the three informal settlements.

These user groups were questioned about their interest in using showers, how much they would be willing to pay per visit for toilets and showers and their opinions about how other aspects of the area around the proposed bio-centres could be improved for example, solid waste management. They were also asked on how other businesses can be developed around and linked to the bio-centre to create a development hub.

\section{Selection of (Physical) Sites and Operating Groups}

The project involved the development of 20 bio-centres in Korogocho (Figure 2), Mukuru and Kibera. The first step in the groups selection is through a rigorous competition and the groups are shortlisted depending on the membership, registration, activities, availability of space involved among other factors. The top selected groups then take the technical team for site identification and this is done considering the location of the site, vicinity of other toilets and closeness to residents (beneficiaries). 
To enhance cost-effectiveness, the sites were clustered into four groups for purposes of training.

Once the groups were selected members were trained in eco-san promotion, biocentres and community cookers along with the initial training of promoters in water and sanitation. The purpose of training the promoters was to assist in successive training of the rest of the community members. A series of user awareness workshops were held over the project period run by UT and the operating groups' promoters. During the construction phase operating group members were trained in basic business skills and how to operate and maintain the bio-centre and its related incomegenerating activities. Currently, the groups are managing the bio-centres, doing the operation and maintenance.

Figure 2: A Map of Korogocho

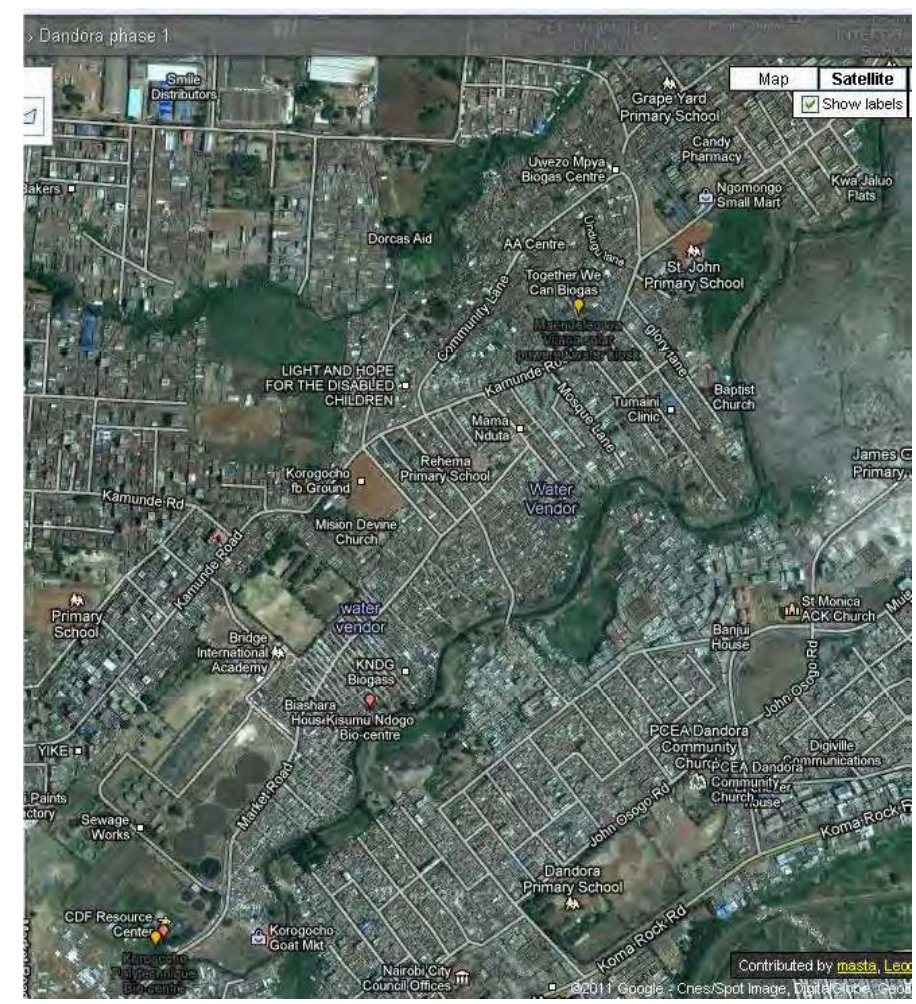

Source: Ministry of Lands, Nairobi City Council, UN-HABITAT (Korogocho Upgrading program)

\section{Bio-centre Construction}

Using the information gathered from the initial research combined with stakeholders input, the toilets design was finalized. It was agreed that the design would be that of bio-centres as this is the standard design developed by UT over the construction of two existing latrines in Nairobi's Kibera informal settlement. The designs have two bathrooms for both male and female users and four toilets on each side. The human investment (waste) is directed into an underground dome which goes through anaerobic digestion and produces biogas as well as liquid fertilizer. This biogas system and building construction was supervised by UT and members of the operating group actually participated in the construction of the facility. They were trained, on and off 
the job, by staff and community artisans from Kibera who had been trained during the previous implementation of bio-centre projects.

\section{Community Capacity Building Process}

21 Apart from the construction process, UT have maintained a process-based capacity building approach that has seen community groups acquire and develop skills in governance, community-led design, budgeting, procurement and supervision of works. UT is also equipping artisans with skills in bio-sanitation through on-the-job training. The capacity building process has utilized skills drawn from other informal settlements in Nairobi as part of peer education. Exchange visits continue to take place during this period as part of community-to-community learning.

This process of capacity building has been achieved through trainings. Various committees were selected amongst the group members and they become the representatives of the members. Each group has four committees: (1) executive; (2) business management; (3) tendering and (4) works, each comprising of five members. They are tasked with roles and responsibilities by their members who hold them accountable during their group meetings.

The management committees were trained on:

\section{i) Governance}

24 The committees were trained on group membership, existence and role of project committees, existence of a site manager, leadership skills, communication, feedback mechanism, management of WATSAN services, work plans and financial management (budgeting, procurement and supervision of works).

\section{ii) Hygiene Promotion}

Hygiene and clean environment is the ultimate goal of this project and this can only be realized through regular cleaning of the facilities. The training emphasized the importance of:

- Removal of mud from the shoes before entering the toilet. All the groups were asked to ensure that the facilities have a door rack.

- Use of soaps/detergents: The trainees were informed that not all the soaps and detergents could be used in cleaning the facility because some were not friendly to the bacteria that are necessary for bio gas production.

- Regular cleaning of the facility to avoid stenches and create habitable surroundings.

\section{iii) Detection}

The trainings also emphasized on the importance of detecting and preventing:

- Gas leakage: The groups were trained on how to monitor gas levels and also how to detect leakages.

- Blockage in the gas pipe: The groups were taught how to detect and remove the water from the pipes using water traps.

- Blockage of the soil water channel: The groups were also taught on how to unblock the channels and also in safe disposal of sanitary towels to avoid blockage. 


\section{iv) Biogas Systems}

The groups were introduced to safety measures with regard to biogas systems which included: lighting the match stick before releasing the gas and keeping the burner clean to ensure proper burning of the gas.

\section{v) Filters}

The committees were informed on the importance of filters and the need to keep them clean. They were advised to regularly remove any dry matter on the mesh above the filter.

\section{Information and communication}

Project team members have been using all available opportunities, through day to day contact with all stakeholders which include community members, to share on project progress and seek for ways of fast tracking activities. Progress reports were shared with all stakeholders involved especially AWSB. A household survey was conducted in areas adjoining each bio-centre. This process provided a chance for awareness creation on the project activities and also an opportunity to collect residents' perceptions on improving access to water and sanitation services.

\section{Decision Making/Participation}

Since the approach to bio-centres is community participation and involvement in all steps of implementation, there are several lessons we have learnt through the process:

\section{i) Extensive communication and transparent closure of project in project cycle management enables the following achievements}

- The sense of ownership has been enhanced making the community to take responsibility of the projects.

- Consultations improved the relationships between the community and the service providers which in turn lead to better decisions. It allowed people interested in or affected by projects to offer their views before a decision is made.

- A set of outcomes desired by the community has been achieved.

- There is a reduced chance of conflicts which is not only costly but an outcome of a dissatisfied community.

- The community was given a role in the implementation.

- The trust and approval of the community involved is secured.

- It is a rewarding way to get to know the community, their needs, ideas and wants.

- Ensured that the local project benefits the local community.

- Consultations have increased stakeholders' commitment to the project and generate a greater willingness for stakeholders to invest their time labor and other resources in a project they own.

- It is important to be close to the community so that they will let you know if you are doing the wrong thing. For instance, dissuading a contractor from constructing on a sewer line on 
a road reserve that s/he may not have been aware of as houses may have invaded the way. It provides more accurate and detailed information which otherwise may be difficult to obtain.

- It establishes stakeholders' records as stakeholders' circumstances will change over time and their relationship to the project will also change during the designing, monitoring or evaluation of a project.

- It is very essential for sustainability as those given the tasks to manage specific projects handle them in such a manner that will ensure the projects run in the long term.

\section{ii) Innovations}

The community was trained on innovative approaches such as:

- Brick making: from each of the three settlements, 130 community members i.e. 48 female and 82 male, were trained on brick making. These were members of the 20 Community-based Organisations (CBOs) implementing the NWSEPIP in their settlements. These bricks were used to build the dome that harnesses the human wastes and the gas.

- Dome construction: another 47 people were trained on dome construction in all the twenty sites. Dome construction is a new practice in Kenya and was quite exciting. The training target persons were the masons who were identified by the communities. However, this new practice attracted even 4 women who were employed as unskilled laborers and they too acquired the skill in the process.

- Block Laying: Block laying skills were imparted to the artisans who were trained on dome construction. Again the targets here were the masons who were laying the blocks. This training was on-going during the entire construction period because the trainers routinely visit the sites and give advice to the masons.

Figure 3: Dome Construction

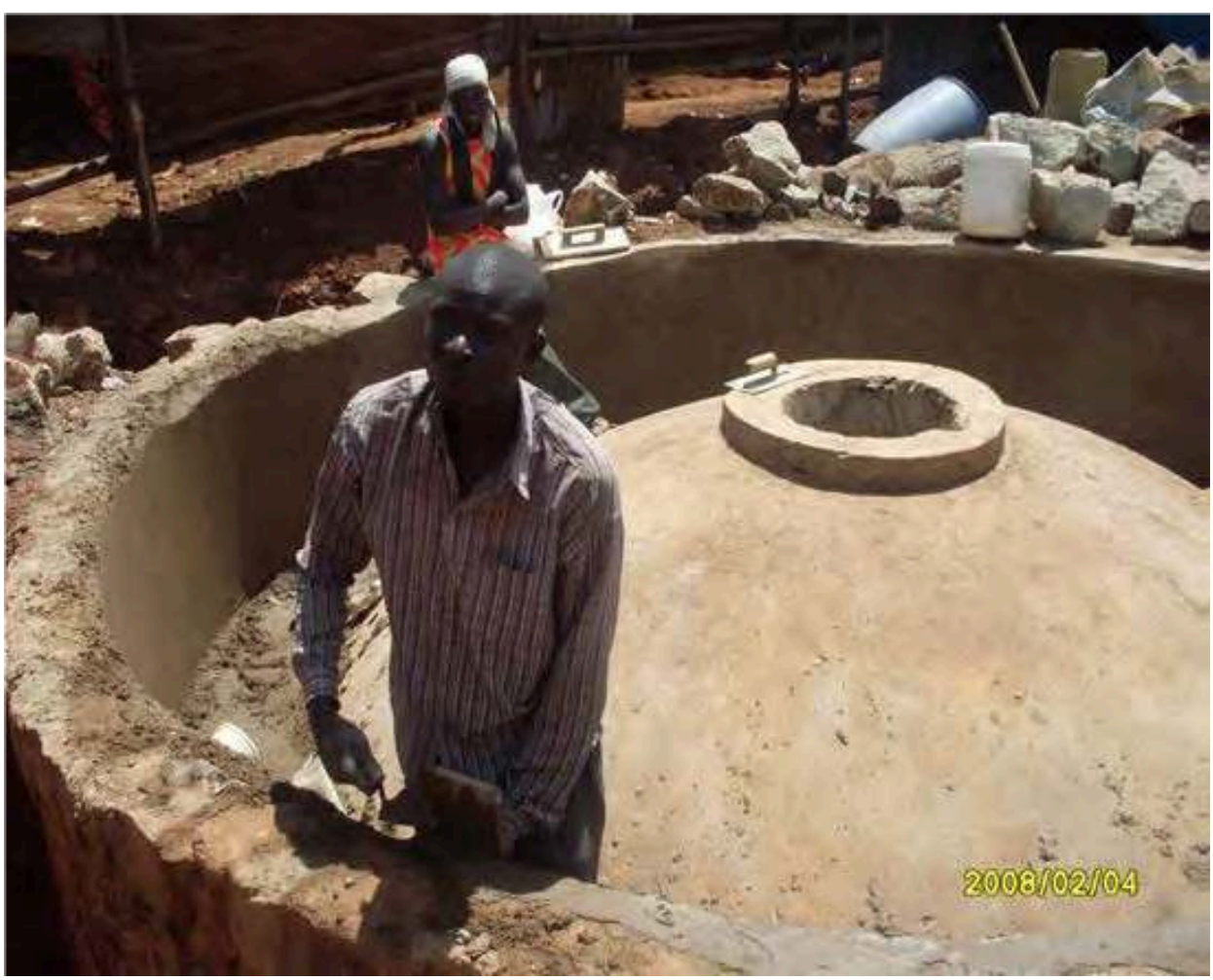

Source: Umande Trust (2008) 
Figure 4: Brick making

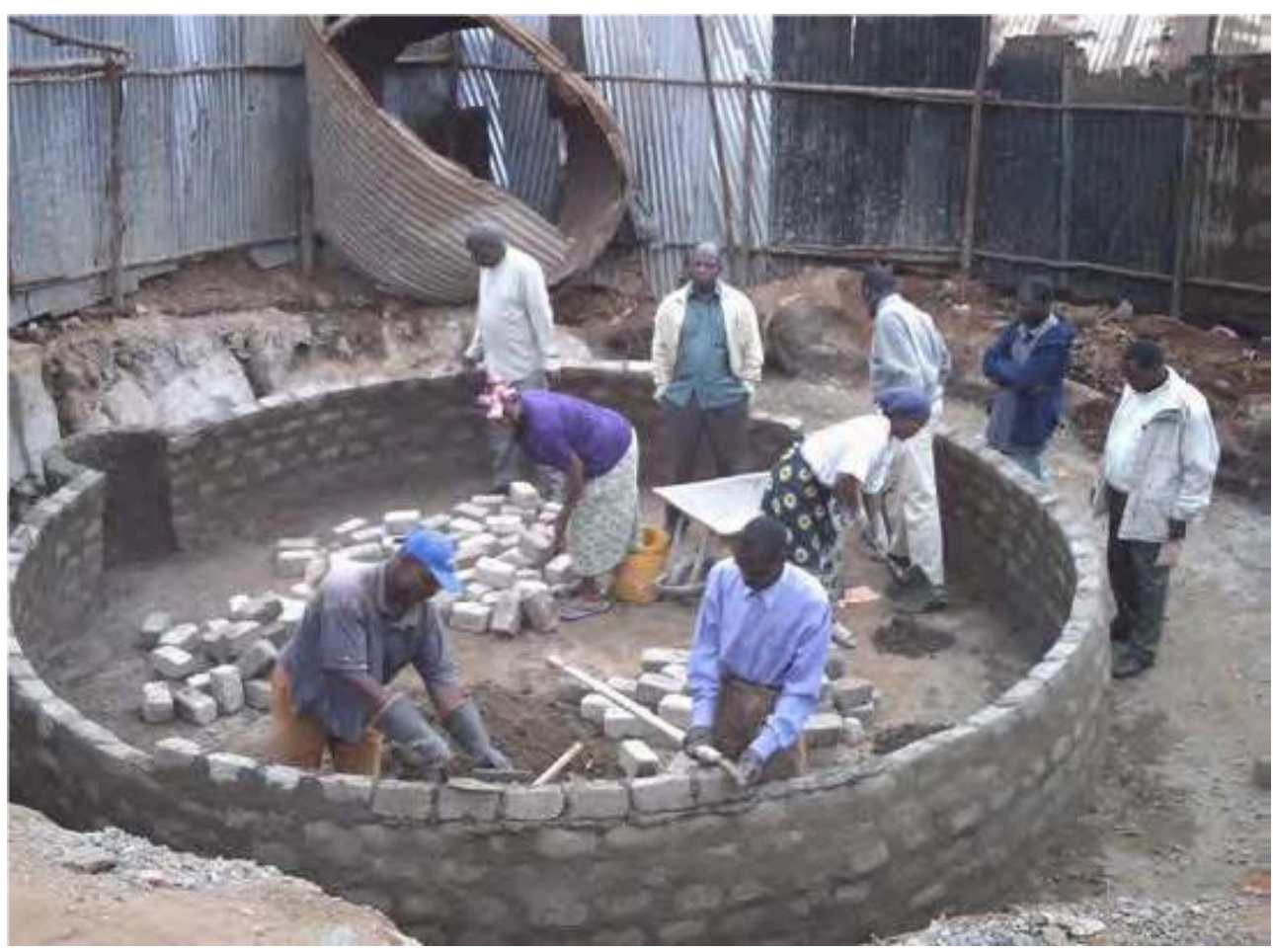

Source: Umande Trust (2008)

Block Laying: Block laying skills were imparted to the artisans who were trained on dome construction. Again the targets here were the masons who were laying the blocks. This training was on-going during the entire construction period because the trainers routinely visit the sites and give advice to the masons.

\section{Project Constraints}

Inasmuch as there were considerable achievements made in the bio-centre project, the following constraints were experienced:

- There have been delays in disbursement of funds slowing down construction work as material suppliers were reluctant to deliver materials to the sites mainly due to nonpayment.

- The political unrest after the 2007 Kenyan General Elections compromised the safety of those working on the sites including UT technicians. In this same period, some groups suffered setbacks due to the displacement of key group members who were holding project leadership posts.

- Availability of construction materials, especially dressed stones, for superstructure works was faced by the community procurement committees due to a workers strike that had crippled operations at the quarry sites.

- In Mukuru, the paths were impassable therefore hindering delivery of materials thus slowing down construction activities.

- The cost of construction for all of the ablution blocks was way above the budgeted amount. The structures implemented have mostly one storey, as opposed to the design as per the contract that was supposed to be only on the ground floor. This is mainly attributed to the 
pressure the community put on UT to implement the meeting rooms and kitchen. This was an additional project by itself, with massive costs in the construction of the staircase, floor slab and additional floor.

- The supervision of the community was difficult and some groups did not follow instructions. In Mukuru, one of the employees stole money and this case was taken to court.

- There were cases of insecurity leading to theft of construction materials in some sites.

- Most of the excavation was done during the rainy season and surface water drained into the excavation.

- Land ownership issues: land on which the bio-centres are constructed belongs to the Kenyan government while some in Mukuru settlement is private owned. Prior to the construction, groups are asked to apply for the bio-centre. One of the requirements that the group has to have during the application exercise is some proof of space that has been approved by the area authorities which is shown by a letter allocating the space from the local administration. One of the major changes in land ownership is the support given to the groups by the administration which represents the government at the grassroots level.

\section{Results and Impact}

\section{Social Impact}

- Accessibility: The ablution blocks have improved people's lives enabling them to have access to water and sanitation facilities hence improving their health and reducing diseases such as cholera. On average, 450 people visit the centres every day.

- Privacy: Privacy has been enhanced as there are separate bathrooms and toilets for women and men i.e. four toilets and two bathrooms for each gender.

- Security: Security has improved especially for women and children as the facilities are situated near the households. The predicament of flying toilets that crammed the paths is now being eradicated as people adopt the good waste management practices by using the available sanitation facilities.

- Sensitization: Hygienic practices have been enhanced with hygiene education in the schools and in the community being carried out through door-to-door sensitization.

- Responsibility: Landlords are providing for sanitation facilities as they build housing units.

- Ownership: Communities now have a sense of ownership, having been involved in the project processes which have also made them responsible for the facilities.

- Gender issues: With water being accessible, women do not have to devote their time searching for water; they can now engage in other economic generating activities that will uplift them, and their households, economically.

- Decision making: Gender equality and equity in decision-making, resource-allocation and programme design and implementation has been enhanced by the program as more women are in the planning committees of these ablution blocks.

- Hygiene: The hand wash sinks in the facilities have increased hygiene levels among the beneficiary community members. There are two side taps in each centre which have increased hygiene through hand washing after visiting the toilet. There is also improvement in household and personal hygiene through regular bathing and washing of clothes.

- Respect: The ablution blocks have supplied water next to the toilets so as to respect the practices of Muslims who clean themselves with water after visiting the toilet. 
- Social integration: The ablution blocks have taken women, children, the physically challenged and People Living with Aids (PLWA) into consideration therefore reducing exclusion.

\section{Economic Impact}

- Capacity building: Arising from the project's capacity development strategy, over 200 members (women, men and the youth) have developed skills in accountability sessions, promoting hygiene, leadership, procurement and tendering procedures, record keeping, financial management and reporting.

- Income: The self-help groups managing the facilities have been able to get profits by providing services to the community through running their bathrooms, toilets, hall hire and water businesses at a fee. On average, the group makes approximately KSh 1,600 (USD 17) per month from the ablution block and the facilities are managed by the beneficiary groups.

- Job creation: The program has created jobs and the skills transferred ensure that some members of local communities become skilled bricklayers, painters and they also learn how to mix concrete and fit ceilings therefore improving their economic dependence.

- Affordability: Water from other sources is 1.6 times more expensive than the bio-centre water. The average saved amount per month per household totals to KSh 271 (USD 3) which represents one day's wage for a casual worker or $4.6 \%$ of the monthly expenditures of the poorest households. These affordable services have left the community with increased disposable income therefore increasing their savings and investing capacities.

- Savings: The community members have benefited from improved hygiene therefore reducing the occurrence of diseases as a result of poor hygiene consequently reducing cases of hospitalization and increasing their disposable income. Community-based groups have embarked on daily saving schemes which have promoted a culture of savings, enhanced trust, improved information flow and established a robust savings scheme where eligible members can secure modest loans to support their small-scale businesses. The scheme also attracts additional income for improving the members' livelihood.

- Sanitation credit: UT and the communities have formed Sanitation Development Fund (SANDEF) which allows communities that have benefited from bio-centers to contribute $10 \%$ of the net income into the kitty. The fund will get other sources of income from the partners forming it, local authority funds, other willing donors and the Government. SANDEF is a selfsustaining fund which loans out, rather than grants, the funds needed to undertake a sanitation project. Government and Non-governmental Organizations (NGOs) can make a donation to SANDEF rather than to a specific project. After a project is completed, the loan will be repaid to SANDEF and those funds can be loaned out again for another project hence multiplies the impact of donations. Despite the clear demand by the community for better water and sanitation, the shortage of available funds has made this development nearly impossible. When donors can be found, their donations are given as grants. This negatively impacts sustainability as donors constantly need to be found. SANDEF ensures that the community can get funds on its own to do minor repairs and support other low-cost sanitation options.

\section{Environmental Impact}

- Clean energy: The project promotes renewable energy application by shifting from fuelwood to biogas for cooking, which in turn improves energy efficiency, reduces carbon dioxide emissions and alleviates pressure on forests. 
- Awareness creation: The project promotes environmental awareness and education at the informal settlement level.

- Capacity building: The project builds the capacity of the community on environmental project management. Good and affordable sanitation facilities are integrated with proper education leading to the eradication of flying toilets and enabling a good environment for people to live in.

- Tree planting: The project has initiated a plan to plant trees around the bio-centres.

\section{Lessons Learnt}

- Poor communities aspire to live in a clean environment and are ready to use their resources to achieve it or pay a small fee to use decent, clean toilets and bathrooms.

- Community participation in the management of services creates a sense of ownership and increases their responsibility while partnerships enhance the realization of goals that would otherwise be difficult to achieve. This project demonstrates successful collaboration among NGOs, local authorities, international agencies, the private sector and communities, in water and sanitation for the urban poor.

- The facility has helped residents to perceive human waste as a resource through application of affordable and socially acceptable technologies for energy production.

- Replication depends on sponsors due to high investment cost.

- Community group dynamics play a major role in the construction activities this is due to the participatory planning, tendering, procurement and building process. Certain groups have managed to adopt this process with very little challenges. This is evident by the rate at which construction works progressed per site.

- Construction with people requires much more monitoring since efforts are required in ensuring accountability, information flow and book keeping.

- Community artisans need close guidance especially where critical stages of construction are reached to ensure structures are built according to desired specifications.

- Compliance with legal and institutional frameworks: As stipulated in the Water Act (2002), AWSB is the asset holding and management entity guided by the AWSB 2007 pro-poor policy. This project seeks to respond to the challenge of supporting WATSAN services in informal settlement, while recognizing community efforts in improved on-site sanitation and hygiene. It is important to note that this project presents a mixed-ownership arrangement between AWSB and community members whose details need to be understood and communicated to group members.

In conclusion, the initiative has attracted local and international stakeholders' interest and participation. Encouraged by the benefits of bio-centres, these stakeholders in partnership with UT are replicating the project on a larger scale which continues to boost the bio-sanitation technology in Africa. 


\section{BIBLIOGRAPHY}

Government of Kenya [GOK]. 2009. Kenya Population and Housing Census. Nairobi: Kenya National Bureau of Statistics.

\section{NOTES}

1. One of 43 languages of Kenya.

\section{ABSTRACTS}

The aim of this article is to present a case study of bio-centres in three slums in Nairobi: Korogocho, Kibera and Mukuru in an approach developed by Umande Trust (UT) which is seeking to improve access to basic urban services to affected communities. To-date, 49 bio-centres have also been constructed in Kisumu and Nairobi. It is hoped that this approach will attract future replication of the technology in other parts of the country. This article gives a background to the Trust and outlines the objectives, strategies, successes and challenges experienced in the course of this slum upgrading effort.

\section{INDEX}

\section{Geographical index: Kenya}

\section{AUTHOR}

\section{AIDAH BINALE}

Monitoring \& Evaluation and Geographical Information Systems (GIS) officer, Umande Trust, Nairobi, Kenya. 